王玥, 周旺明, 王绍先, 牛丽君, 代力民.CLUE-S 模型在长白山自然保护区外围规划中的应用.生态学报, 2014,34(19):5635-5641.

Wang Y, Zhou W M, Wang S X, Niu L J, Dai L M. Application of land use model CLUE-S in the planning of surrounding the Changbai Mountain Biosphere Reserve. Acta Ecologica Sinica, 2014,34(19):5635-5641.

\title{
CLUE-S 模型在长白山自然保护区外围规划中的应用
}

\author{
王 玥 ${ }^{1,2}$, 周旺明 ${ }^{1}$, 王绍先 ${ }^{3}$, 牛丽君 ${ }^{3}$, 代力民 ${ }^{1, *}$ \\ (1 . 森林与土壤生态国家重点实验室,中国科学院沈阳应用生态研究所,沈阳 110016 ; \\ 2. 沈阳建筑大学管理学院, 沈阳 $110168 ; 3$. 长白山科学研究院, 吉林省长白山保护开发区, 吉林 133613)
}

\begin{abstract}
摘要:受自然保护区旅游业快速发展影响,长白山自然保护区外围土地利用变化加剧。因此,对区域土地利用布局进行科学规 划具有十分重要的意义。以长白山自然保护区外围 $30 \mathrm{~km}$ 区域为研究对象,探讨了 CLUE-S 模型在小尺度土地利用规划中的 应用。在分析研究区 1991-2007 年土地利用变化的驱动力基础上,根据区域规划预案,模拟 2020 土地利用布局。利用模拟结 果划定空间管制区和乡镇布局,并与现有规划进行了对比。结果表明,基于 CLUE-S 模型的土地规划明显抑制了区域景观破碎 化进程,减弱了人为活动对景观的影响,该方法可以为长白山区域土地利用规划提供有力的技术手段和科学支撑。
\end{abstract}

关键词: CLUE-S 模型; 土地利用规划; 长白山自然保护区

\section{Application of land use model CLUE-S in the planning of surrounding the Changbai Mountain Biosphere Reserve}

\author{
WANG Yue ${ }^{1,2}$, ZHOU Wangming ${ }^{1}$, WANG Shaoxian ${ }^{3}$, NIU Lijun ${ }^{3}$, DAI Limin ${ }^{1, *}$ \\ 1 State Key Laboratory of Forest and Soil Ecology, Institute of Applied Ecology, Chinese Academy of Sciences, Shenyang 110016, China \\ 2 Management School of Shenyang Jianzhu University, Shenyang 110168, China \\ 3 Changbai Mountain Academy of Sciences, Changbai Mountain Protection and Development Zone of Jilin Province, Jiling 133613, China
}

\begin{abstract}
Ecological tourism frequently serves as an important tool for economic development in areas adjacent to forest and other types of nature reserves. The infrastructure for ecological tourism is usually constructed in the area immediately surrounding the reserve in accordance with relevant reserve regulations. This will clearly affect the local ecosystem. The study of land use changes surrounding nature reserves may provide guidance and a scientific basis for reasonable and effective land-use planning in these areas. Simulation models can be a scientific and effective tool in understanding and predicting changes in spatial patterns of land use over time, providing precise scenarios for changes in spatial patterns that can be used in regional land use planning. CLUE-S is one such model widely used in the study of land use change, and is particularly effective in simulating shifting patterns of land use in small scale areas. The Changbai Mountain Biosphere Reserve (CMBR) is an important forest nature reserve in Northeastern China. In recent years, extensive land-use and landcover change, triggered by rapid development of tourism and the expansion of townships, has occurred in the area surrounding the CMBR. Among previous research on landscape changes in the CMBR, relatively little attention has been given to the scientific planning of land use. Focusing on the area consisting of all land within $30 \mathrm{~km}$ of the CMBR, this study explored the application of CLUE-S in land use planning on a small scale. Utilizing Landsat TM data from 1991 and 2007, and referring to master and regional planning documents for Changbai Mountain, a multiple of $600 \times 600$ grids was used to calculate the area of each land use type. The spatial scale was $600 \mathrm{~m}$ and the time of simulation was set as 2020 . The
\end{abstract}

基金项目:国家林业公益性行业专项(201104070)；中国科学院战略性先导科技专项(XDA05060200)

收稿日期: 2013-01-14; 网络出版日期:2014-03-07

*通讯作者 Corresponding author.E-mail: lmdai@iae.ac.cn 
driving forces of land use change were analyzed by logistic regression. Using the model to simulate the evolution of land use changes, it was tested with a Kappa index of 0.949. The landscape for the area in 2020 was then simulated, and a land use plan was provided according to the urban planning scenario in the study area. The simulated landscape in 2020 showed that $16488 \mathrm{hm} 2$ of cultivated land and forest is projected to be converted to developed land, which extended to the area around the current site. We delimited the control zones, arrangement pattern and development direction of townships based on CLUE-S simulation results. Analysis of the landscape pattern showed that the land use plan based on the simulation results for 2020 using the CLUE-S model had less patches and higher landscape shape index than the landscape pattern during 1991-2007. This indicates that the land use plan of the CLUE-S model restrained the process of landscape fragmentation and reduced human-induced disturbances. Compared to the existing plan, the land use plan of the CLUE-S model took the surrounding area as a whole and chose the maximum probability of alternative areas according to the demand for developed land. It also had a smaller number of new towns and developed land area, which contributed relieving stresses on the environment. The CLUE-S model appears to be a powerful, scientifically-based technical means to support in land use planning efforts on a small scale.

Key Words : CLUE-S model; land use planning; Changbai Mountain Biosphere Reserve

近年来,森林生态系统类型自然保护区大力发 展生态旅游项目。但由于基础设施和旅游配套设施 的建设受《自然保护区条例》的限制, 只能建在保护 区外围, 需要占用保护区边缘及邻近外围乡镇大量 土地,这势必会加快这些区域的土地利用变化以及 对区域资源环境的影响 ${ }^{[1-4]}$ 。针对自然保护区边缘 地带研究, 国外关注于边缘地带的人口变化研究 ${ }^{[5]}$; 国内,仅有薛其福分析研究了九寨沟自然保护区周 边土地利用/土地覆被变化 ${ }^{[6]}$ 。长白山自然保护区 作为东北地区重要的旅游景点, 近些年来游客增长 迅速, 导致自然保护区周边土地利用变化加剧。但 已有长白山地区土地利用和景观格局研究多以自然 保护区内作为研究对象 ${ }^{[7-12]}$, 而保护区外围土地利 用变化研究仅有从林业局尺度分析人口增长和修建 旅游设施对区域森林资源产生的影响 ${ }^{[13]}$ 。因此, 针 对长白山自然保护区外围土地利用变化的研究以及 制定合理的区域土地利用规划具有十分重要意义。

模型方法是土地利用格局变化预案模拟研究的 有效科学工具, 较为精确的模拟结果可以用于区域 土地利用规划。CLUE-S 模型是土地利用变化研究 中广泛使用的模型 ${ }^{[14-19]}$, 基于土地利用与驱动因子 之间的定量关系, 对区域内各种土地利用类型之间 的竞争进行系统动力学仿真, 在模拟土地利用时空 动态方面具有明显的优势, 能较好地模拟小尺度范 围内土地利用变化情景, 具有更高的可信度和更强
的解释能力 ${ }^{[20-21]}$ 。本文应用 Logistic 回归分析了自 然保护区外围土地利用变化的驱动力, 将 CLUE-S 模型模拟结果应用于区域土地利用规划中, 为科学 规划提供定量数据分析和技术手段。

\section{1 研究地区与研究方法}

\section{1 研究区概况}

长白山自然保护区 $\left(41^{\circ} 41^{\prime} 49^{\prime}\right.$ - $42^{\circ} 25^{\prime} 18^{\circ}$ N, $127^{\circ} 42^{\prime} 55^{\prime}$ - $128^{\circ} 16^{\prime} 48^{\prime}$ E ) 地处吉林省的东南部, 总面积为 $196465 \mathrm{hm}^{2}$, 是自然环境和生态系统保存 最为完整的森林生态系统保护区之一, 在吉林省旅 游中占有重要地位。20 世纪 80 年代, 最初旅游人数 仅为近 3 万人, 到本世纪初增长到 20 万人, 2010 年, 国内外游客已到 244 万人次, 10 年间旅游人数翻了 10 倍, 2010 年实现旅游收人 20.3 亿元, 是 2006 年旅 游收人的 4 倍。

本研究区域为长白山自然保护区外围 $30 \mathrm{~km}$ (图 1)。研究区域内有 10 个乡镇, 5 个森工企业, 分 别为二道白河镇、露水河镇、两江镇、松江河镇、松江 镇、泉阳镇、漫江镇、东岗镇、十四道沟镇、长白镇及 白河林业局、露水河林业局、泉阳林业局、松江河林 业局、长白森林经营局。十四道沟镇和长白镇位于 长白山自然保护区以南, 距保护区界直线距离近 30 $\mathrm{km}$, 地形复杂, 与保护区交通通达性较差, 受保护区 旅游影响较小, 故本研究中不予考虑。 


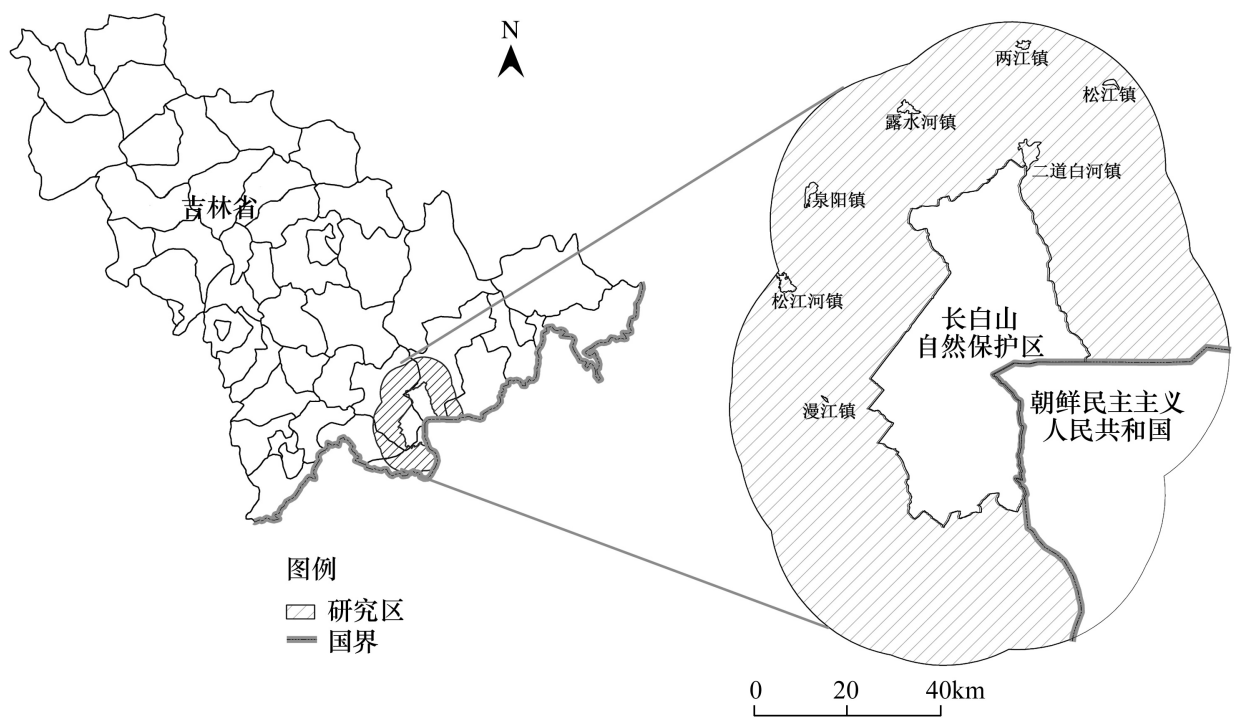

图 1 研究区位置图

Fig.1 Location of study area

1.2 数据采集

数据源选用 Landsat TM 遥感影像,包括 1991 年

5 月和 2007 年 10 月。应用遥感分析软件 ERDAS 9.2 , 以研究区林相图作为参照, 采用监督分类方法,
分别对 1991 年和 2007 年两期影像进行解译, 得到 相应的土地利用图(图 2)。应用实地采样点余下的 260 个采样数据对两期的解译结果进行精度评价, 精 度分别为 $90.2 \%$ 和 $93.4 \%$ 。

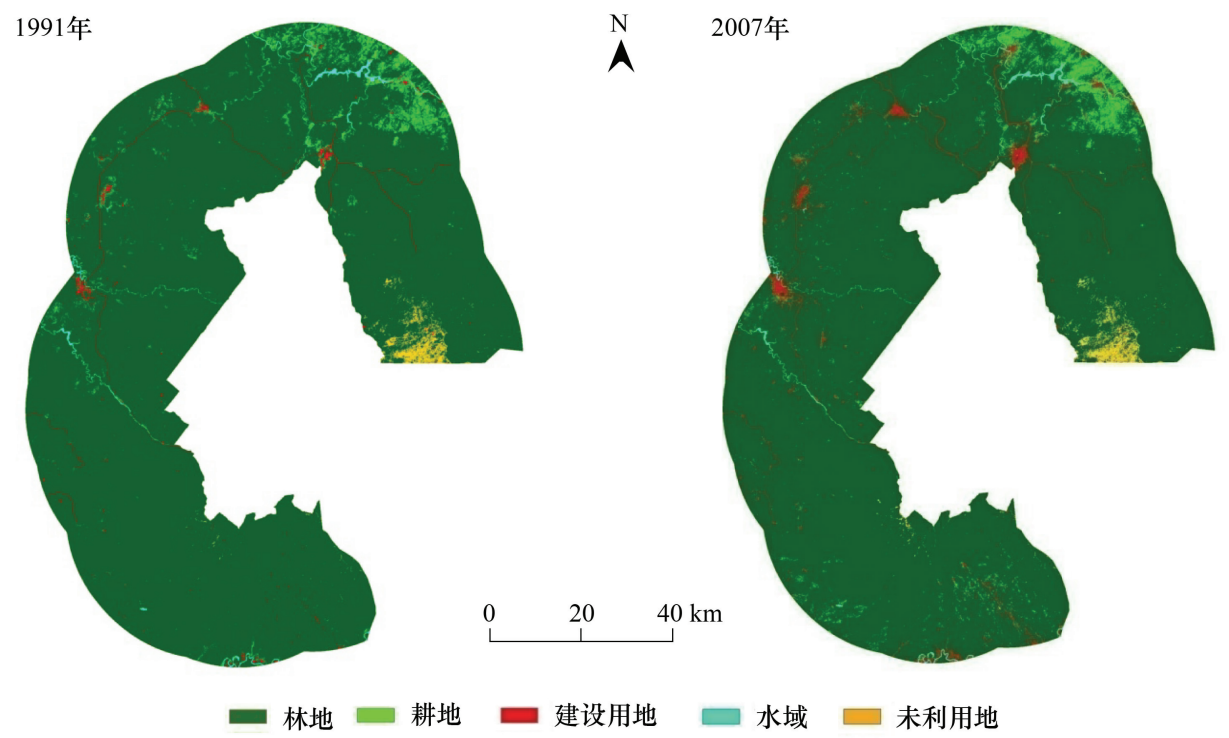

图 21991 和 2007 研究区土地利用图

Fig.2 Land use map of study area in 1991 and 2007

根据研究目的, 将研究区土地利用分为五种类 型: 林地、耕地、建设用地、水域和未利用地。设定水 域掩膜, 以避免人为误差 ${ }^{[22]}$ 。分类体系中, 林地界 定为郁闭度大于 $10 \%$ 的有林地、迹地以及苗圃; 建设 用地包含居住、工业、商业、交通等用地; 未利用地含 荒草地、裸岩以及郁闭度小于 $10 \%$ 林地。

\subsection{CLUE-S 模型}

CLUE-S 模型是荷兰瓦赫宁根大学“土地利用变 化和影响” 研究小组在 CLUE 模型的基础上开发的。 该模型分为两个不同模块, 非空间需求模块和空间 分配模块。非空间需求模块土地利用变化的计算基 于统计层次,而空间分配模块基于栅格系统将土地 
需求转化为土地利用变化分配到研究区域的不同空 间位置 ${ }^{[23]}$ 。

1.4 模型数据和参数设置

\subsection{1 预案设定}

基于结果可对比的研究目的,设定城镇总体规 划预案。依据长白山总体规划和区域乡镇规划, 按 照 $600 \times 600$ 栅格倍数确定到 2020 年各土地利用类 别的面积, 然后根据线性插值方法确定 2007-2020 各年份土地利用变化, 以此作为模型中土地需求 参数。

\subsection{2 空间和时间尺度的确定}

根据熵理论, 相同研究区内的高空间分辨率比 低空间分辨率包含更多的熵, 能够体现更多的细节 信息,但同时也将导致预测不确定性的增加,从而使 结果准确率较低 ${ }^{[16]}$ 。基于 CLUE-S 模型中示例的默 认参数, 从 $1000 \mathrm{~m}$ 分辨率 $($ 栅格大小为 $1000 \mathrm{~m} \times$ $1000 \mathrm{~m}$ ) 开始, 以 $100 \mathrm{~m}$ 为步长提高空间分辨率。
结果表明,在研究区 CLUE-S 模型最高可运行的分辨 率为 $600 \mathrm{~m}$ 。因此, 本研究选择的空间尺度为 $600 \mathrm{~m}$ 。

我国新一轮地利用总体规划和城市总体规划 期末年均为 2020 年,为了增强结果的应用性和可对 比性,将模型模拟目标年设定为 2020 年。

\subsection{3 空间驱动力}

依据资料可获取性、因子变异性、因子可量化 性,同时考虑研究区地处自然保护区外围,绝大部分 土地利用类型为有林地,主要选取地形因子、邻域因 子、交通可达性因子和人口因子 (表 1 )。对二元 Logistic 回归方程的解释能力一般用 Pontius R.G. 提 出 ROC (Relative Operating Characteristics) 方法进行 检验。检验指标 ROC 值介于 0.5 和 1 之间,一般认 为当 $R O C$ 值大于或等于 0.70 时方程的拟合优度较 高, 反之则相对较低。

表 1 各土地利用类型的 logistic 回归结果 (Beta 值)

Table 1 The Beta value of logistic regression

\begin{tabular}{lcccc}
\hline $\begin{array}{l}\text { 驱动因子 } \\
\text { Driver factors }\end{array}$ & $\begin{array}{c}\text { 建设用地 } \\
\text { Developed land }\end{array}$ & $\begin{array}{c}\text { 耕地 } \\
\text { Cultivated land }\end{array}$ & $\begin{array}{c}\text { 林地 } \\
\text { Forest }\end{array}$ & $\begin{array}{c}\text { 未利用地 } \\
\text { Open land }\end{array}$ \\
\hline 到公路的距离 Distance to road & 0.00001 & 0.0001 & -0.00005 & -0.0004 \\
到城镇的距离 Distance to city & 0.00001 & -0.0001 & 0.00004 & 0.0003 \\
到保护区的距离 distance to reserve & -0.00001 & 0.00008 & -0.00002 & -0.0005 \\
到河流的距离 Distance to stream & -0.00002 & -0.00003 & -0.00003 & 0.0002 \\
到铁路的距离 Distance to railway & 0.000005 & -0.000002 & -0.000007 & 0.0001 \\
海拔 Elevation/m & -0.005 & -0.005 & 0.005 & -0.005 \\
坡度 Slope & -0.049 & -0.011 & 0.013 & 0.01 \\
人口密度 Population density/(人/hm $\left.{ }^{2}\right)$ & 0.053 & 0.003 & -0.054 & -0.74 \\
常数 Constant & 0.293 & -0.464 & -0.823 & -10.613 \\
受试者工作特征曲线 ROC $($ Relative Operating Characteristics) & 0.801 & 0.855 & 0.749 & 0.981 \\
\hline
\end{tabular}

\subsection{4 模型验证}

模型的验证以 1991 年作为初期,模拟 2007 土 地利用类型图, 将模拟结果与 2007 年实际土地利用 类型模拟对比,验证模型精度。比较模拟的 2007 年 土地利用图与解译得到的 2007 年土地利用图, 其 Kappa 指数为 0.949 ,表明模型对自然保护区外围土 地利用演变模拟精度较高。

\section{2 结果}

\section{1 模拟结果}

模拟结果是在驱动因子的综合作用下, 反映各
种土地利用类型之间相互竞争及其在空间分配上的 演替规律。在城市规划预案下以 2007 年为基准年, 模拟 2007-2020 年土地利用分布 (图 3)。各种用地 类型随时间的推移大多在原有位置附近发生了一定 程度的扩张与收缩。为了满足 2020 年土地利用需 求,保护区以西外部原有零散耕地转变为建设用地, 共分配 $7632 \mathrm{hm}^{2}$ 耕地调减为建设用地。研究区南部 部分林地转变为建设用地, 总计 $8856 \mathrm{hm}^{2}$ 林地转变 为建设用地,使得区域建设用地沿原有建设用地向 四周扩散,但从总体上看,未大规模连片集中。 


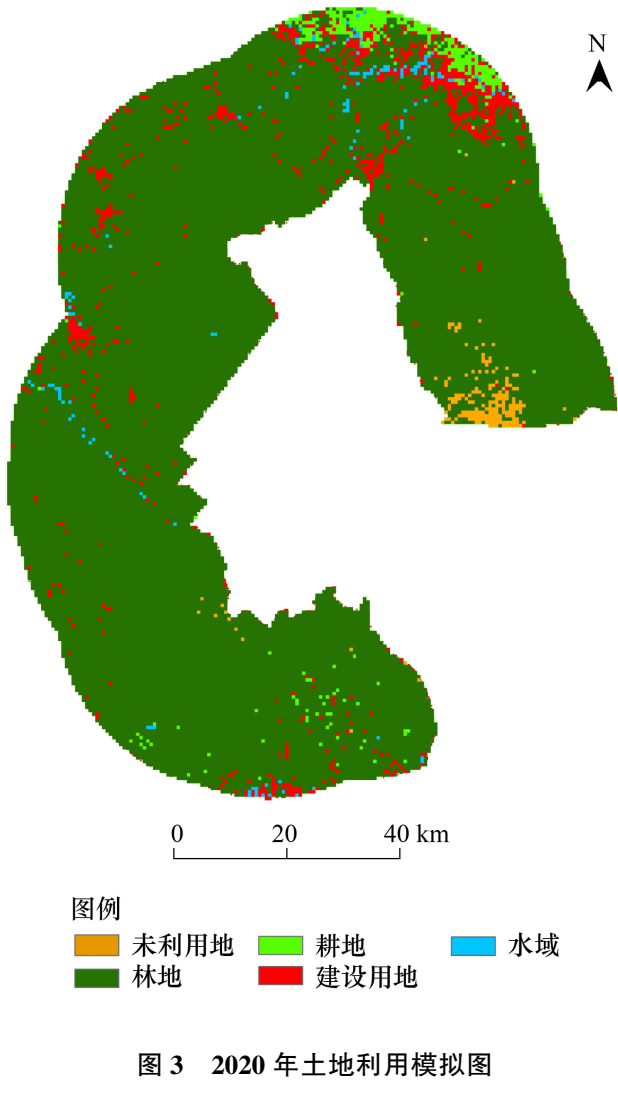

Fig.3 The simulation map of land use in 2020

2.2 空间管制和乡镇布局规划

将研究区内珍惜资源保护地、水源保护地、保护 区外旅游景区划人限建区。依据 CLUE-S 模型的模 拟结果, 在建设用地密集分布区内, 根据旅游活动的 主题功能和乡镇分布划定适建区 (图 4); 旅游活动 主题功能区是长白山旅游活动的可建区域。

根据模拟结果确定 2020 年乡镇布局区域和发 展方向 (图 5)。研究区 7 个乡镇以原有建设用地为 中心向不同方向扩张, 泉阳镇和露水河镇扩展空间 较小。松江镇从道路、交通、地形等自然条件看,有 很大的转换空间, 其外围土地均可为了适应需求而 转换利用方式。模拟结果在二道白河镇和松江镇之 间给出了大面积的建设用地布局, 为了满足研究区 2020 年建设用地需求, 该区域既可以作为建设新区 的选址地,也可以作为松江镇发展扩张区域。

\section{3 讨论}

3.1 规划结果景观格局指数分析

根据景观格局指数的意义和敏感性,选取斑块 数量、景观形状指数、多样性指数和聚集度指数 4 个 指数在景观水平上从数量、形状和分布 3 个方面评

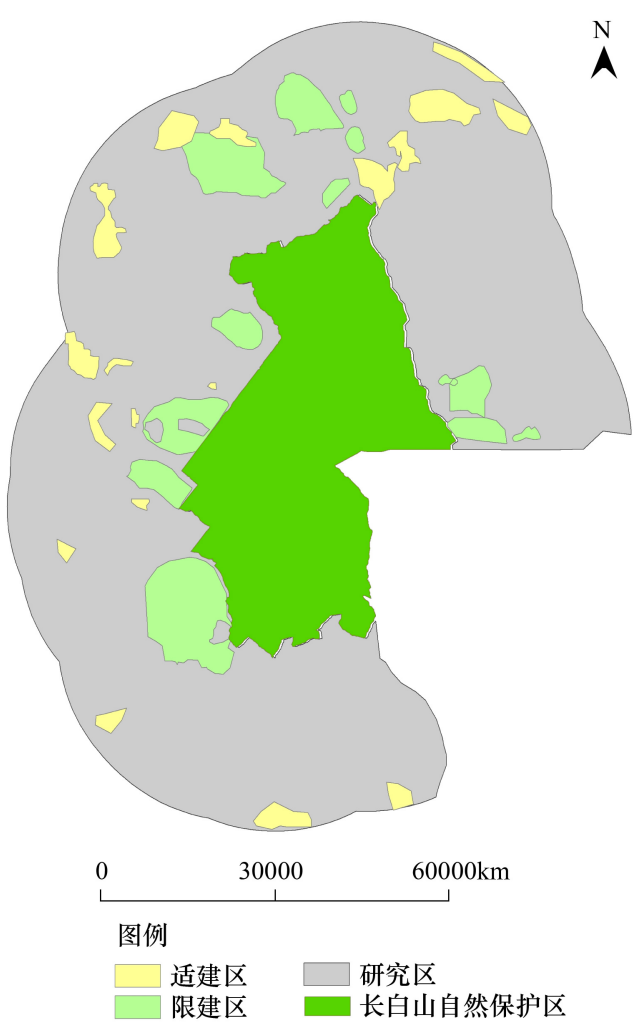

图 4 研究区空间管制分区图

Fig.4 Land control zoning in study area

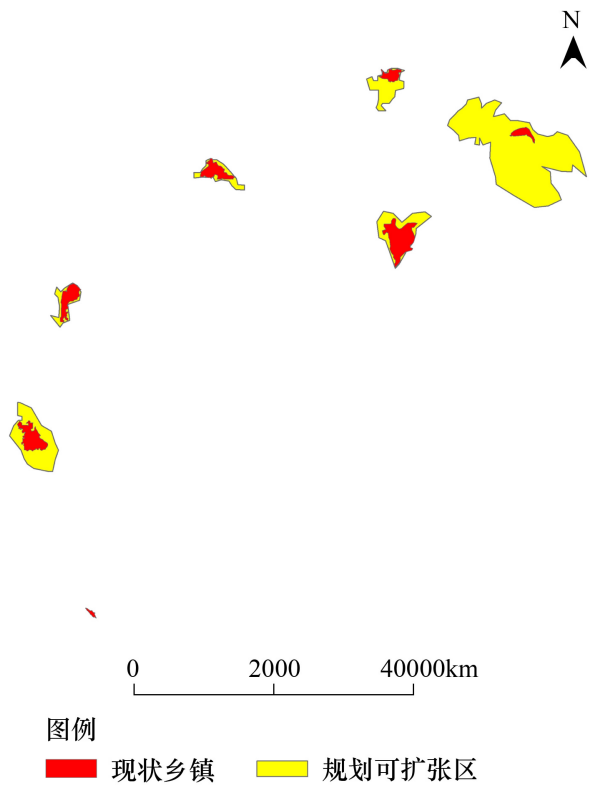

图 5 乡镇布局规划图

Fig.5 Townships pattern plan

价格局变化 ${ }^{[16]}$ 。

1991-2007 年,研究区景观的斑块数量、景观形 状指数增加, 表明整个景观破碎化程度增加, 景观异 质性更加明显。景观多样性指数由 0.2641 增加到 
0.3276 , 聚集度指数由 0.9253 下降到 0.9090 , 表明各 类景观组分面积比例差别在逐渐缩小, 景观中林地
组分优势程度减弱, 人类活动对于生态环境的影响 随着时间推移不断加剧 (表 2)。

\section{表 2 研究区景观格局指数及变化}

Table 2 The total eigenvalue of the landscape pattern in 1991, 2007 and 2020

\begin{tabular}{|c|c|c|c|c|}
\hline $\begin{array}{l}\text { 年份 } \\
\text { Year }\end{array}$ & $\begin{array}{c}\text { 斑块数量 } \\
\text { Number of Patches }\end{array}$ & $\begin{array}{c}\text { 景观形状指数 } \\
\text { Landscape Shape Index }\end{array}$ & $\begin{array}{l}\text { 聚集度指数/\% } \\
\text { Aggregation Index }\end{array}$ & $\begin{array}{c}\text { 多样性指数 } \\
\text { Shannon's Diversity Index }\end{array}$ \\
\hline 1991 & 467 & 7.0461 & 92.5265 & 0.2641 \\
\hline 2007 & 562 & 8.2321 & 90.9094 & 0.3276 \\
\hline 2020 & 522 & 8.2799 & 90.8757 & 0.3675 \\
\hline 1991-2007 变化 Change of 1991－2007 & 95 & 1.186 & -1.6171 & 0.0635 \\
\hline 2007-2020 变化 Change of $2007-2020$ & -40 & 0.0478 & -0.0337 & 0.0409 \\
\hline
\end{tabular}

对比两个阶段景观特征指数 ( 1991-2007, 2007-2020), 2007-2020 阶段斑块数量减少了 40, 景观形状指数增加 0.0478 ,均小于 1991-2007 变化 量, 表明土地利用规划明显抑制区域景观破碎化进 程,有方向性的土地利用和规划会减弱人为活动对 景观的影响。

\section{2 模拟结果与规划图比较}

研究区已制定的规划为《长白山总体规划 (2006-2020)》，《抚松新城总体规划（20102030)》。将上述规划整合,长白山保护区外围(含研 究区) 将形成如下规划布局(图 6)。

模拟结果 (图 3 ) 在保护区以北二道白河镇和松 江镇之间给出了大面积的建设用地布局。规划图 (图 6) 在保护区以西建设生态新城, 面积约是模拟 结果的两倍。造成这一差异的主要原因是规划图由 县级以上政府制订,长白山自然保护区外围行政机 构 (抚松县、长白山管委会、安图县) 均注重区域旅游 发展对经济的拉动作用,在各自行政管辖区域内建 设生态旅游新城。而模拟结果将保护区外围视为统 一整体, 按照建设用地需求量选择空间上最大概率 转换区域,因此模拟结果新城数量和建设用地面积 均小于规划图。

保护区外围存在多个行政主体, 为了分享旅游 发展的经济收益,均在保护区不同方向提出了侧重 旅游的总体规划。规划图 (图 6) 在长白山保护区西 部和北部将建设两大生态新城, 与周围乡镇形成网 络群,这势必对区域生态环境保护带来严重压力。

\section{4 结论}

CLUE-S 模型是土地利用规划的前期分析和用

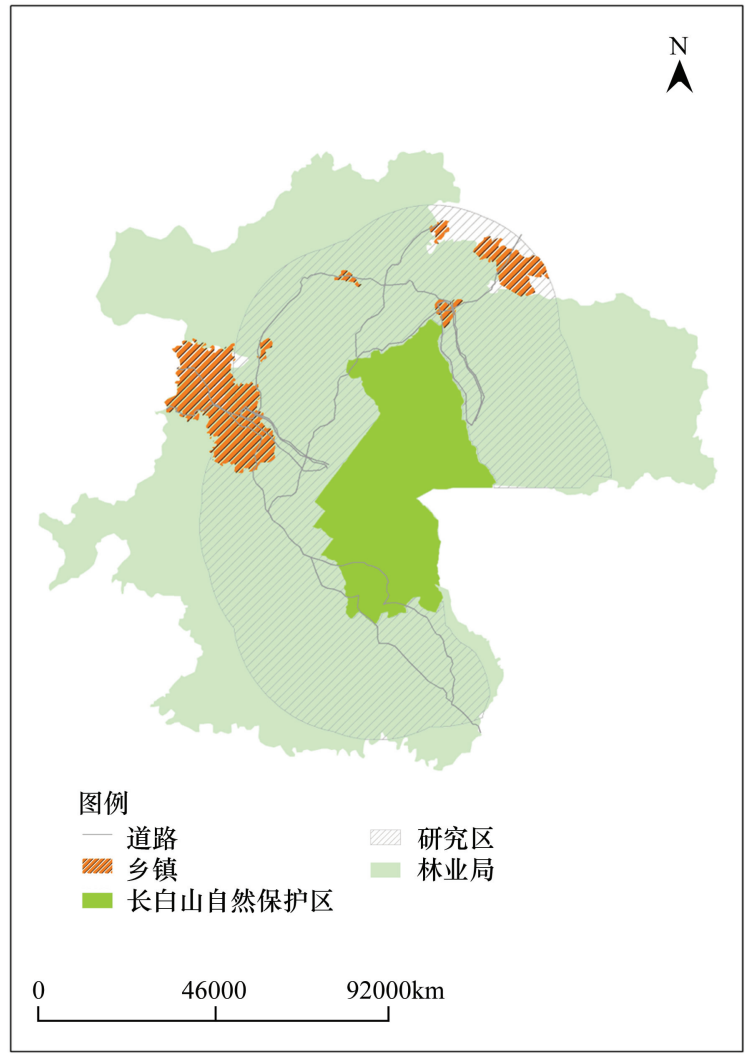

图 6 长白山保护区外围规划整合图

Fig. 6 Master Plans surrounding Changbai Mountain Biosphere Reserve integrated

地配置的有力工具。在土地利用规划过程中, 引人 景观评价方法是行之有效的，有助于改善传统规划 中单纯土地适宜性评价提供的信息不足和对规划评 价的定量指标不足的弱点, 在促进规划和评价的定 量化过程中有重要的实践意义。

长白山自然保护区外围行政机构在各自城市规 划中不同程度的提出发展旅游配套产业和设施, 以 此增强区域的吸引力, 个体角度规划或许适宜,但从 
区域整体出发,规划具有一定片面性。建议保护区 管理体制上统一,无论从财政拨款、单位建制、人事 安排、还是从投资收益均划归单一部门,范围以外围 紧邻林业局为界。保护区外围总体规划方案的制定 必须统一规划与布局,正确处理保护与开发、旅游与 教育、资源保护区与社区发展等关系。

\section{References :}

[ 1 ] Burak S, Dogan E, Gazioglu C. Impact of urbanization and tourism on coastal environment. Ocean \& Coastal Management, 2004, 47(9/10): 515-527.

[ 2 ] Cengiz T. Tourism, an ecological approach in protected areas: Karagol-Sahara National Park, Turkey. International Journal of Sustainable Development and World Ecology, 2007, 14 (3): 260-267.

[ 3 ] Don R C, Yu L J, Liu G H. Impact of tourism development on land-cover change in a matriarchal community in the Lugu Lake area. International Journal of Sustainable Development and World Ecology, 2008, 15(1) : 28-35.

[ 4 ] Li X Y, Ma Y J, Xu H Y, Wang J H, Zhang D S. Impact of land use and land cover change on environmental degradation in lake Qinghai Watershed, Northeast Qinghai-Tibet Plateau. Land Degradation \& Development, 2009, 20(1): 69-83.

[ 5 ] Wittemyer G, Elsen P, Bean W T, Burton A C O, Brashares J S. Accelerated human population growth at protected area edges. Science, 2008, 321 (5885) : 123-126.

[6] Xue Q F. Tourism, Urbanization and Their Impacts on Land Use and Cover-A Case Study in Jiuzhaigou Country [D]. Beijing: Peking University, 2004.

[ 7 ] Chang Y, Bu R C, Hu Y M, Xu C G, Wang Q L. Dynamics of forest landscape boundary at Changbai Mountain. Chinese Journal of Applied Ecology, 2004, 15(1) : 15-20.

[ 8 ] Zheng D L, Wallin D O, Hao Z Q. Rates and patterns of landscape change between 1972 and 1988 in the Changbai Mountain area of China and North Korea. Landscape Ecology, 1997, 12(4) : 241-254.

[ 9 ] Yu D Y, Hao Z Q, Pan Y Z, Jiang P, Yie J. Evaluation on forest resources utilization in typical forest region of Changbai Mountains. Acta Ecologica Sinica, 2004, 24(12) : 2940- 2944.

[10] Tang L N, Shao G F, Piao Z J, Dai L M, Jenkins M A, Wang S X, Wu G, Wu J G, Zhao J Z. Forest degradation deepens around and within protected areas in East Asia. Biological Conservation, 2010, 143(5) : 1295-1298.

[11] Tang L N, Li A X, Shao G F. Landscape-level forest ecosystem conservation on Changbai Mountain, China and North Korea Mountain Research and Development, 2011, 31(2): 169-175.

[12] Liu X M, Bu R C, Deng H W, Hu Y M, Liu Z H, Wu Z W. Estimation and spatial pattern analysis of forest biomass in Fenglin Nature Reserve based on Geostatistics. Acta Ecologica Sinica, $2011,31(16): 4783-4790$.

[13] Zhao J Z, Li Y, Wang D Y, Xu D. Tourism-induced deforestation outside Changbai Mountain Biosphere Reserve, northeast China. Annals of Forest Science, 2011, 68(5) : 935-941.

[14] Sun X F, Yue T X, Fan Z M. Simulation of the spatial pattern of land use change in China: the case of planned development scenario. Acta Ecologica Sinica, 2012, 32(20) : 6440-6451.

[15] Pan Y, Liu Y H, Wang J, Yu Z R. Non-point pollution control for landscape conservation analysis based on CLUE-S simulations in Miyun County. Acta Ecologica Sinica, 2011, 31(2) : 529-537.
[16] Liu M, Hu Y M, Sun F Y, Li C L, Xu Y Y, Zhou Y. Application of land use model CLUE-S in the planning of central Liaoning urban agglomerations. Chinese Journal of Ecology, 2012, 31(2) : 413-420.

[17] Liu M, Hu Y M, Chang Y, He H S, Bu R C. Analysis of temporal predicting abilities for the CLUE-S land use model. Acta Ecologica Sinica, 2009, 29(11): 6110-6109.

[18] Sheng S, Liu M S, Xu C, Yu W, Chen H. Application of CLUE$\mathrm{S}$ model in simulating land use changes in Nanjing metropolitan region. Chinese Journal of Ecology, 2008, 27(2) : 235-239.

[19] Zhou R, Su H L, Hu Y M, Li Y H, Liu M. Scenarios simulation of town land use change under different spatial constraints. Transactions of the Chinese Society of Agricultural Engineering, 2011, 27(3): 300-308.

[20] Zhou R, Su H L, Wang X J, Li Y H, Hu Y M, Zhang F E, Xu B H. Simulation and accuracy assessment of village land use change based on CLUE-S model. Resources and Environment in the Yangtze Basin, 2012, 21(2): 174-180.

[21] Wu J S, Feng Z, Gao Y, Huang X L, Liu H M, Huang L. Recent progresses on the application and improvement of the CLUE-S model. Process in Geography, 2012, 31(1) : 3-10.

[22] Salvati L, Sabbi A. Exploring long-term land cover changes in an urban region of southern Europe. International Journal of Sustainable Development and World Ecology, 2011, 18 (4): 273-282.

[23] Verburg P H, Veldkamp A, de Koning G H J. A spatial explidt allocation procedure for modelling the pattern of land use change based upon actual land use. Ecological Modelling, 1999, 116 (1) : 45-61.

\section{参考文献:}

[6] 薛其福. 旅游带动型城市化对保护区所在地自然资源的影 响——橧沟县的土地利用 $/$ 覆被变化为例 $[\mathrm{D}]$. 北京: 北 京大学, 2004.

[ 7 ] 常禹, 布仁仓, 胡远满, 徐崇刚, 王庆礼. 长白山森林景观边 界动态变化研究. 应用生态学报, 2004, 15(1) : 15-20.

[9] 于德永, 郝占庆, 潘耀忠, 姜萍, 叶吉. 长白山典型林区森林 资源利用状况评价. 生态学报, 2004, 24(12)：2940-2944.

[12] 刘晓梅, 布仁仓, 邓华卫, 胡远满, 刘志华, 吴志伟. 基于地 统计学丰林自然保护区森林生物量估测及空间格局分析. 生 态学报, 2011, 31(16) : 4783-4790.

[14] 孙晓芳, 岳天祥, 范泽孟. 中国土地利用空间格局动态变化模 拟一一以规划情景为例. 生态学报, 2012, 32(20): 6440-6451.

[15］潘影, 刘云慧, 王静, 宇振荣. 基于 CLUE-S 模型的密云县面 源污染控制景观安全格局分析. 生态学报, 2011, 31(2)： 529-537.

[16] 刘沝, 胡远满, 孙风云, 李春林, 徐岩岩, 周媛. 土地利用模 型 CLUE-S 在辽宁省中部城市群规划中的应用. 生态学杂志, 2012, 31(2) : 413-420.

［17］刘沝, 胡远满, 常禹, 贺红士, 布仁仓. 土地利用模型时间尺 度预测能力分析一以 CLUE-S 模型为例. 生态学报, 2009, 29(11) : 6110-6109.

［18］盛晟, 刘茂松, 徐驰, 郁文, 陈虹. CLUE-S 模型在南京市土地 利用变化研究中的应用. 生态学杂志, 2008, 27(2) : 235-239.

[19] 周锐, 苏海龙, 胡远满, 李月辉, 刘沝. 不同空间约束条件下 的城镇土地利用变化多预案模拟. 农业工程学报, 2011, 27 (3) : 300-308.

[20] 周锐, 苏海龙, 王新军, 李月辉, 胡远满, 张风娥, 许博涵. CLUE-S 模型对村镇土地利用变化的模拟与精度评价. 长江流 域资源与环境, 2012, 21(2)：174-180.

[21] 吴健生, 冯喆, 高阳, 黄秀兰, 刘洪萌, 黄力. CLUE-S 模型应 用进展与改进研究. 地理科学进展, 2012, 31(1) : 3-10. 